Preference is given to letters commenting on contributions published recently in the JRSM. They should not exceed 300 words and should be typed double spaced

\section{Triggering of thyroid hormone autoantibodies}

The case report by Dr Chan and colleagues (October 2002, $J R S M^{1}$ ) reminds us of a similar case we described twenty years ago ${ }^{2}$. Although Chan et al. did not demonstrate formally the nature of the circulating substance that caused the inter-assay discrepancy in free thyroxin (T4) measurement, it is very likely to have been autoantibody to T4, not crossreacting with $\mathrm{T} 3$.

The case is of particular interest to us because of the underlying non-thyroid disease and the transience of the antibodies, which Chan et al. relate to short-term treatment with interferon-alpha. Their patient was being treated for a haematological malignancy (chronic myelogenous leukaemia). So was ours (Waldenström's macroglobulinaemia), in whom we demonstrated circulating thyroid hormone autoantibodies of both $\operatorname{IgM}$ and $\operatorname{IgG}$ classes which preferentially bound $\mathrm{T}^{2}{ }^{2}$. Thyroid assays were discrepant, and, to add to the similarity, our patient was hypothyroid (thyroid stimulating hormone $40 \mathrm{mU} / \mathrm{L}$, antithyroglobulin negative). This patient had been treated with prednisone and an alkylating drug (cyclophosphamide) which we now know can transiently disturb thyroid hormone metabolism ${ }^{3}$. Because the patient died, we cannot know whether the thyroid hormone binding autoantibodies would have been transient or permanent.

In light of our recent work in this field ${ }^{4-8}$, we believe that there is a common triggering mechanism between the two patients ${ }^{1,2}$. Description of this mechanism requires mention that our patient also had circulating autoantibodies against steroid hormones which are transported by the corticosteroid-binding globulin $(\mathrm{CBG})^{9}$. Concerning the patient of Chan et al. we think that interferon-alpha caused the same thyroid cytotoxic effects as those caused by cytokines produced by and released from the lymphocytes that infiltrate the thyroid ${ }^{10}$, resulting ultimately in release of iodinated heterogeneous molecules of thyroglobulin $(\mathrm{Tg})$ with T4 exposed on their external surface. The cytokine effects are reversible, so that the said release of $\mathrm{Tg}$ molecules ends when interferon-alpha treatment is stopped. With regard to our patient, alkylating drugs probably caused transient release of T4 from non-thyroid pools, especially from the liver, even when administered in association with corticosteroids ${ }^{3}$.

We postulate that alkylating drugs might also cause release of other molecules, including the serine protease inhibitors (SERPINs) such as the liver-synthesized alpha ${ }^{-}$ antitrypsin, alpha ${ }_{1}$-antichymotrypsin and CBG. SERPINs are acute phase reactants that increase under conditions such as inflammatory or neoplastic processes ${ }^{11}$ and can bind thyroid hormones ${ }^{12}$. Perhaps the cyclophosphamide-induced release of a SERPIN with both steroid and thyroid hormone binding capacity, in a patient who was under treatment with corticosteroids, somehow incited appearance of autoantibodies capable of interacting with both steroids and thyroid hormones.

\section{Salvatore Benvenga}

\section{Francesco Trimarchi}

Sezione di Endocrinologia del Dipartimento Clinico-Sperimentale di Medicina e Farmacologia, University of Messina School of Medicine, Policlinico Universitario, padiglione $\mathrm{H} 4$ piano, 98125 Messina, Italy

Correspondence to: S Benvenga

E-mail: s.benvenga@me.nettuno.it

\section{REFERENCES}

1 Chan BW, Chow CC, Cockram CS. Discrepant thyroid function tests in a patient treated with interferon-alpha. J R Soc Med 2002;95:506

2 Trimarchi F, Benvenga S, Fenzi GF, Mariotti S, Consolo F. Immunoglobulin binding of thyroid hormones in a case of Waldenström's macroglobulinemia. J Clin Endocrinol Metab 1982;54: 1045-50

3 Reinhardt W, Sauter V, Jockenhovel F, et al. Unique alterations of thyroid function parameters after iv administration alkylating drugs cyclofosfamide and ifosfamide. Exp Clin Endocrinol Diabetes 1999;107:177-82

4 Trimarchi F, Benvenga S, Costante $\mathrm{G}$, et al. Identification and characterization of circulating thyroid autoantibodies in thyroid disease, in autoimmune non-thyroid illnesses and in lymphoreticular disorders. J Endocrinol Invest 1983;6:203-9

5 Benvenga S, Trimarchi F, Robbins J. Circulating thyroid hormone autoantibodies. J Endocrinol Invest 1987;10:605-19

6 Benvenga S, Bartolone L, Squadrito S, Trimarchi F. Thyroid hormone autoantibodies elicited by diagnostic fine-needle biopsy. J Clin Endocrinol Metab 1997;82:4217-23

7 Ruggeri RM, Galletti M, Mandolfino MG, et al. Thyroid hormone autoantibodies in primary Sjögren syndrome and rheumatoid arthritis are more prevalent than in autoimmune thyroid disease, becoming progressively more frequent in this disease. J Endocrinol Invest 2002;25: 447-54

8 Benvenga S, Burek CL, Talor M, Rose NR, Trimarchi F. Heterogeneity of the thyroglobulin epitopes associated with circulating thyroid hormone autoantibodies in Hashimoto's thyroiditis and nonautoimmune thyroid diseases. J Endocrinol Invest (in press)

9 Benvenga S, Trimarchi F, Barbera C, Consolo F. Abnormal cortisol binding in a case of Waldenström's macroglobulinemia. $N$ Engl J Med 1980;303:1179-80

10 Weetman AP. Chronic autoimmune thyroiditis. In: Braverman LE, Utiger RD, eds. Werner and Ingbar's the Thyroid. Philadelphia: Lippincott Williams \& Wilkins, 2000:719-32

11 Ingenbleek Y. Thyroid function in nonthyroid illnesses. In: De Visscher M, ed. The Thyroid Gland. New York: Raven Press, 1980:499-527

12 Benvenga S, Lapa D, Trimarchi F. Thyroxine binding to members and non-members of the serine protease inhibitors. J Endocrinol Invest $2002 ; 25: 32-8$ 


\section{Illegible handwriting in medical records}

Dr Rodríguez-Vera and colleagues (November 2002, JRSM ${ }^{1}$ ) say that, if doctors cannot be persuaded to write legibly, the answer is computerization. This might indeed be a useful strategy for eliminating errors attributable to illegible handwriting, but the health record is beset by troubles of a more fundamental nature, requiring more imaginative solutions. Some of these arise from the fact that problem lists, action plans, and problem-oriented medical records have not been universally accepted in our medical culture, either at medical school or in so-called continuing professional development ${ }^{2-4}$. Without the implementation and continual updating of problem lists, drug lists (including adverse reactions), and action plans, the health record soon degenerates into a tedious litany, devoid of both structure and purpose. Furthermore, when hospital records become voluminous ${ }^{4}$ with chaotic filing thrown in for good measure (i.e. 'anything' filed 'anywhere' and 'anyhow') there is a formidable disincentive to attempting anything more than a cursory review of previous clinical episodes. Computerization will only make matters worse, thanks to the axiom 'rubbish in, rubbish out' and the limited flexibility of the present generation of healthcare computers ${ }^{4}$. Finally, since neither clinic letters nor discharge summaries are routinely audited, and in view of the reported proliferation of errors of omission and factual inaccuracies in some of the correspondence emanating from secondary care ${ }^{5}$, the electronic record might end up as a system for perpetuating misleading documentation.

\section{O M P Jolobe}

Department of Adult Medicine, Tameside General Hospital, Ashton-under-Lyne OK6 9RW, UK

\section{REFERENCES}

1 Rodríguez-Vera FJ, Marín Y, Sánchez A, Borrachero C, Pujol, E. Illegible handwriting in medical records. J R Soc Med 2002;95:545-6

2 Lloyd BW, Barnett P. Use of problem lists in letters between hospital doctors and general practitioners. BMJ 1993;306:247

3 Melville C, Hands S, Jones P. Randomised trial of the effects of structuring clinic correspondence. Arch Dis Child 2002;86:374-5

4 Benson T. Why do general practitioners use computers and hospital doctors do not: part 2, scalability. BMJ 2002:325:1090-3

5 Macaulay EM, Cooper GG, Engeset J, Naylor AR. Prospective audit of discharge summaries. Br J Surg 1996;83:788-90

\section{Anonymized dysgraphia}

Dr Rodríguez-Vera and colleagues (November 2002, $J R S M^{1}$ ) found that a substantial proportion of clinical records were unclear because of poor handwriting. In the UK, the General Medical Council says that doctors must keep clear, accurate, legible and contemporaneous patient records which report the decisions made and keep colleagues well informed when sharing the care of patients ${ }^{2}$. Good communication between colleagues requires sufficient note-taking as well as legible handwriting. We conducted a survey of the post-take ward round entries in the case notes of 100 patients at Derriford Hospital, Plymouth. We studied the communication in the notes between the admitting team and the doctors who ultimately look after the patients. In $42 \%$ of cases the presumed diagnosis (following a consultant's review) was not recorded. Despite a management plan being recorded in $89 \%$ of the notes, in $43 \%$ there was room for doubt as to whether investigations had been requested or merely proposed. These communication failures were compounded by the fact that in 53\% of the records the doctor's name was either illegible or not documented, so that the doctor could not be contacted to clarify the management plan.

It is the responsibility of the doctor to write clear and accurate patient records, something that will not be solved by electronic patient records alone.

\section{Andrew Thompson}

\section{Koshy Jacob}

Jamie Fulton

Derriford Hospital, Plymouth, UK

\section{REFERENCES}

1 Rodríguez-Vera FJ, Marín Y, Sánchez A, Borrachero C, Pujol, E. Illegible handwriting in medical records. J R Soc Med 2002;95:545-6

2 General Medical Council. Good Medical Practice, 3rd edn. London: GMC, 2001

\section{Hereditary somnambulism in Dracula}

I have noticed that Bram Stoker's Dracula ${ }^{1}$ (1897), a multifaceted classic, contains the first known discussion of hereditary somnambulism. Lucy Westenra (who eventually is killed, after becoming a vampire subsequent to having been bitten by Count Dracula) long had a habit of sleepwalking. Moreover Lucy's mother, Mrs Westenra, tells Mina Murray ' . . . that her husband, Lucy's father, had the same habit [sleep-walking], that he would get up in the night and dress himself and go out, if he were not stopped.' Sleep-walking runs in the Westenra family. The next ${ }^{2}$ description of a hereditary component of somnambulism is not until nearly a half century later. More recent studies (e.g. Ref. 3 and references therein) continue to find a hereditary component in somnambulism, though no gene for somnambulism has yet been found.

Dracula abounds with medical content and allusionse.g. blood transfusions, diagnosis-based treatment, David Ferrier (1843-1928), and J-M Charcot (1825-1893). Also, two important figures in the book, John Seward and Professor Abraham Van Helsing, are physicians. Even the vampire legend itself, in Dracula and other stories, may well 
have a medical basis ${ }^{4,5}$ (both vampirism and rabies are infectious conditions characterized by general limbic system derangement in affected individuals, as well as biting and blood-seeking behaviour). Stoker spent orders of magnitude longer on Dracula than on any of his other literary projects - six years compared with a couple of monthsand read widely. Besides being an author, Bram Stoker graduated from Trinity College Dublin with honours in mathematics, and worked as a civil servant and a manager for stage actors (Bram is short for Abraham, and one suspects that Stoker portrays himself in the eccentric, eclectic, and peripatetic genius Professor Van Helsing, who has not only an MD but also a DPh and a DLit and is a lawyer). Also, in writing Dracula Stoker was greatly influenced by Mary Shelley's Frankenstein which was itself imbued with the medical and scientific spirit of James Lind, MD, FRS (1736-1812) via his lectures and contact with Shelley and her husband ${ }^{6}$. It is not known whence or how Stoker came to appreciate the hereditary nature of somnambulism, or why he chose to include the seemingly non-essential detail in Dracula.

\section{Eric Lewin Altschuler}

Mount Sinai School of Medicine, 1425 Madison Avenue, Box 1240, New York, NY 10029; and Brain and Perception Laboratory, University of California, San Diego, USA

E-mail: eric.altschuler@mssm.edu

\section{REFERENCES}

1 Stoker B. Dracula. New York: Modern Library, 2001

2 Davis E, Hayes M, Dirman BH. Somnambulism. Lancet 1942;i:186

3 Kales A, Soldatos CR, Boxler EO, et al. Hereditary factors in sleepwalking and night terrors. Br J Psychiatry 1980;137:111-18

4 Heick A. Prince Dracula, rabies, and the vampire legend. Ann Intern Med 1992;117:172-3

5 Gomez-Alonso J. A possible explanation for the vampire legend. Neurology 1998;51:856-9

6 Goulding C. The real Doctor Frankenstein? J R Soc Med 2002;95:257-9
I have been unable to find any controlled study showing hypoglycaemic effects from traditional medicines such as karela (gourd) powder, or onion and garlic, in the amounts normally consumed. Onion and garlic, being regular ingredients of South Asian diet, are consumed daily by people from that region-who are more, not less, prone to diabetes than the white population of the UK.

'Meditation and prayer tend to lower blood pressure' is another statement that should not be taken at face value. Muslims do not all meditate or pray to the same degree; the individual effects vary and such modalities or their results have not been quantified to predict the necessary adjustment of antihypertensive medicine. Regarding drug therapy in Ramadan, glucosidase inhibitors are the safest drugs for type 2 diabetics and should be used with reduced doses of metformin and sulphonylureas to minimize the risk of glucose fluctuation and acidosis.

Finally, fasting does not always improve diabetes but can make it worse. This has to do with the nature of the disease and patient psychology. Fasting-induced ketosis is a real danger, as is dehydration. Patients may self-adjust the drug timing so as to skip the fasting period. They may reduce or stop medication altogether in the belief that the glucose concentration will not rise in absence of meal and snacks (and God will take care of them during the holy act). They may over-eat at sehri (fast starting meal) to fill up for the day and at iftari (fast ending meal) because of hunger.

To achieve a suitable dose and timing adjustment is not easy. By the time a suitable regimen is devised, most of the Ramadan is gone. For these reasons diabetologists in predominantly Muslim countries discourage patients from fasting unless their disease is well controlled and the patients are well motivated to adapt to changes in their treatment.

\section{Aamir Shahzad}

6 Simon's Court, Lovelace Road, Surbiton KT6 6NE, UK

\section{REFERENCE}

1 Qureshi B. Diabetes in Ramadan. J R Soc Med 2002;95:489-93

\section{Diabetes in Ramadan}

Dr Qureshi (October 2002, JRSM $M^{1}$ ) offers advice on Ramadan fasting in people with diabetes. This is a complex issue, especially for Muslim doctors in whom the scientific facts tend to be mixed with religious considerations. I disagree with some of his 'practical points'.

First, he has confused Muslim dietary laws with decrees on health. There is a consensus amongst Muslim jurists that non-halal products of permitted animals, though undesirable, may be used for medicinal purposes. Bovine insulin was freely used in Pakistan before Humulin became available. Even porcine products are acceptable provided the

\section{Author's reply}

I thank Mr Shahzad for his comments, particularly those relating to the customs of secular Muslims with diabetes. Criticism is a positive activity in science, though not in a religion. Instead of defending one or two points, even by giving references, I would invite other Muslim doctors to participate in constructive debate. With more information we shall be better able to provide high-quality service to patients from all religious and non-religious backgrounds.

\section{Bashir Qureshi}

32 Legrace Avenue, Hounslow West TW4 7RS, UK 


\section{HIV in Africa}

We agree with Mr Loefler (October 2002, JRSM ${ }^{1}$ ) that the HIV disaster has special dimensions in Africa. He contends that 'a change in socioeconomic conditions' is needed to address the pandemic, and accordingly offers a general prescription for ending the postcolonial status of Africa as an exploited society. The implementation of less philosophical responses by organizations such as Global Strategies for HIV Prevention and AMREF by contrast have already registered substantial accomplishments in curbing this disease. One nevirapine tablet given during labour and delivery (followed by a single dose of nevirapine syrup to baby) reduces vertical HIV transmission by $50 \%$. In Tanzania, for example, other multifaceted prevention and treatment approaches have already shown promise by explicitly addressing gender issues that propel the HIV epidemic. Working to make practical programmes such as these function better and reach more people will add considerably to the fight against HIV in Africa, and elsewhere.

When a senior African physician laments 'I know of no medical school in Africa that teaches medical care appropriate to the circumstances in the country'2, then nonAfricans will question why this state prevails there. If it is the case that self-determination has taken African medical schools down a path of medical irrelevancy, then the HIV problem is made needlessly complex. Accordingly, Loefler and other leading African scholars may wish to focus more energy on repairing the local medical education dysfunctions in Africa and on supporting programmes with proven track records in the fight against HIV, rather than on inventing a new world order. Which goals are more likely to be achieved?

\section{E Scott Sills}

Georgia Reproductive Specialists, Atlanta Medical Center, Atlanta, Georgia, USA E-mail: dr.sills@ivf.com

\section{Robert J C Young}

Wadham College, University of Oxford, Oxford, UK

\section{REFERENCES}

1 Loefler I. The contest between a clever virus and a facultatively clever host. J R Soc Med 2002;95:516-7

2 Loefler I. Medical migration. Lancet 2000;356:1196

\section{Consent for autopsy}

With their postal questionnaire, Dr Williams and colleagues found that just $4 \%$ of consultant histopathologists were actively involved in consenting for autopsy and only $20 \%$ expressed a willingness to be involved (November 2002, $\left.J R S M^{1}\right)$. Most histopathologists (89\%) felt that the clinician involved in the patient's care should be responsible for obtaining consent. Clinicians have the advantage of knowing the clinical history and indication for post mortem and may have developed a rapport with the relatives. However, clinicians often have a limited understanding of the process of post mortems and the issues surrounding the retention and disposal of organs and tissues. The pathologist performing the post mortem cannot be sure that consent obtained by a clinician is truly informed.

We are conducting research into sudden unexplained death in young adults, aged 16 to 39 . Our study involves obtaining informed consent from bereaved families to retain tissues and blood from post mortem for research purposes. To provide a recently bereaved relative with the information required for fully informed consent to a post mortem and the retention of organs or tissues is difficult and time-consuming, taking up to 3 hours. This is logistically impossible for both pathologist and clinicians. The public outcry after the Alder Hey and Bristol enquiries has placed informed consent for autopsy and retention of organs and tissue as a major priority. We feel that each trust should have a dedicated trained bereavement adviser, who would be responsible for obtaining informed consent for autopsy and retention of organs/tissues for diagnostic, research or donation purposes. The bereavement adviser would receive training in bereavement counselling, obtaining informed consent, the process of autopsy and issues surrounding retention and disposal of organs/tissues.

They would be an important point of contact for bereaved relatives and would liaise closely with clinicians, pathologists, the coroner and primary care services (e.g. general practitioners and counsellors). A bereavement adviser seems the sensible way to provide a comprehensive service to bereaved relatives. This can only be achieved if the Department of Health supports trusts with extra funding which is ring-fenced for such a bereavement service.

\section{Raj Khiani}

Sarah Shingler

Philip Hasleton ${ }^{1}$

Academic Department of Surgery and ${ }^{1}$ Department of Histopathology, South Manchester University Hospital, Southmoor Road, Manchester M23 9LT, UK

\section{REFERENCE}

1 Williams AT, Morris D, Patel NK. Pathologists' views on consent for autopsy. J R Soc Med 2002;95:547-8

\section{William Budd and typhoid fever}

Dr Moorhead's article (November 2002 JRSM $^{1}$ ) made an enthralling, and for a public health practitioner of today, humbling read. Because the article makes the connection with John Snow it's worth pointing out a tiny error. The modern name of Broad Street (of pump handle fame) is 
Broadwick Street (not Broadhurst). This is worth knowing also to locate The John Snow public house which does not look very inspiring but does have a number of interesting memorabilia and is the meeting place of the John Snow Society (Hon Sec, Dr Ros Stanwell-Smith).

\section{S B Vaile}

63 Joy Lane, Whitstable, Kent CT5 4DD, UK

\section{REFERENCE}

1 Moorhead R. William Budd and typhoid fever. $J$ Soc Med 2002;95:561-4

Like most previous writers on the distinguished career of William Budd (1811-1880), Dr Moorhead (November 2002, $J R S M^{1}$ ) refers to his service with the Seamen's Hospital Society (SHS) on the second of their hospital-ships, HMS Dreadnought, at Greenwich. According to the SHS minutes, his brother George (a physician on the staff of the SHS) recommended William for service with the SHS in a letter to the committee dated 12 August $1840^{2}$. Although not minuted, this advice was presumably accepted. On 21 October 1840, George again wrote to the SHS committee indicating that as William was 'some time laid up with Typhus Fever'; he 'will not [therefore] be able to resume his professional occupation... on board the Dreadnought.' William thus resigned. Although there was much confusion at that time between typhoid and typhus fever, the SHS physicians already possessed a great deal of knowledge of both ${ }^{3}$. Therefore William served at most two months and probably no more than one month with the SHS. This was not therefore a significant component in his overall career.

\section{G C Cook}

11 Old London Road, St Albans AL1 1QE, UK

\section{REFERENCES}

1 Moorhead R. William Budd and typhoid fever. J $R$ Soc Med 2002;95:561-4

2 Cook GC. George Budd FRS (1808-1882): pioneer gastroenterologist and hepatologist. J Med Biog 1998;6:152-9

3 Cook GC. George Leith Roupell FRS (1797-1854): significant contributions to the early nineteenth-century understanding of cholera and typhus. J Med Biog 2000;8:1-7

\section{CORRECTION}

How much do doctors know about consent and capacity?

In this article (December 2002, $J R S M^{1}$ ) the Summary incorrectly states that respondents to the questionnaire included 29 old-age psychiatrists: this should read '29 old-age physicians'.

\section{REFERENCE}

1 Jackson E, Warner J. How much do doctors know about consent and capacity? J R Soc Med 2002;95:598-600 